\title{
STUDY ON CONSERVATION AND RESTORATION OF LIUGOU ANCIENT TOWN EARTHEN SITES IN BEIJING (CHINA)
}

\author{
Z. Gan ${ }^{1}$, L. Long ${ }^{1}$, D. Zhang ${ }^{1, *}$ \\ ${ }^{1}$ Beijing University of Civil Engineering and Architecture, №1 Zhanlanguan Road, Xicheng District, Beijing, China - (strider, \\ longlin)@tntlab.cn, zhangdy@bucea.edu.cn
}

\section{Commission II - WG II/8}

KEY WORDS: Ancient Castle, Earthen Sites, Great Wall, Conservation, Restoration

\begin{abstract}
:
Liugou Ancient Castle located in the southeast of Yanqing District, Beijing. It is an essential castle in the perimeter defence system of the Great Wall. The ancient castle presents a clear square pattern, which is made up of the earthen wall and Brick-encased soil gates, which connected to the earthen Great Wall on the west side. Due to the changes of the times and the influence of natural and human factors, the earthen sites of Liugou Ancient Castle have been damaged to varying degrees, and the conservation and restoration work needs to be entirely carried out. Firstly, this research analysed and summarized the types and conservation status of earthen sites from field investigation results. Secondly, the samples of deteriorations faced by earthen sites and their forming factors are analysed in detail. Finally, based on the principle of "minimum intervention and identifiable," the research puts forward a repair strategy and specific operation technology for various deteriorations, to provide a reference for the future practice of earthen sites restoration, display, and utilization of Liugou Ancient Castle.
\end{abstract}

\section{FEATURES OF LIUGOU ANCIENT TOWN EARTHEN SITES}

The development history of earthen sites extends from the Stone Age to modern times and is an essential type of cultural heritage. In northern China, a large number of earthen sites have been preserved due to the natural environment characteristics such as drought and sparse rainfall. Yanqing area is located along with Beijing's external defence system, with the earthen Great Wall and castles. However, years of disrepair and historical wars have caused some of the masonry of the town walls to fall off, leaving only the parts of the earthen ruins in urgent need of protection and reinforcement.

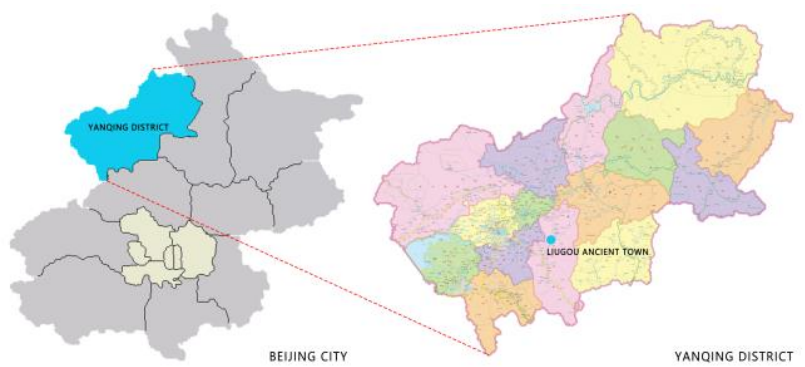

Figure 1. Location of Liugou Ancient Town in Beijing.

\subsection{General Introduction}

The ancient town of Liugou is $15 \mathrm{~km}$ from Yanqing County, $2 \mathrm{~km}$ from Jingzhuang Town Government, and $3 \mathrm{~km}$ from 110 National Highway. The earthen site of Liugou ancient town is the castle site of the Great Wall of the Ming Dynasty, which was connected with the Great Wall.
Liugou, also known as "Phoenix Town" in ancient times, has rich historical content and ancient town culture. According to historical records, Liugou ancient town as an essential gateway of Juyongguan, set up a garrison to take charge of the defence of the imperial mausoleum. The existing castle wall site is rammed earth. There are ground remains at four corners of the town, and the outline of the castle is clear. There is no wall left in Nanguan in the records, and its boundary and shape are unknown.

The west side of the castle is next to the Great Wall, and there are also beacon towers. The relationship between the castle and the surrounding Great Wall and mountain-shaped landforms is evident and apparent. The total area of the town is 6300 square meters. The existing southern town wall is about 375 meters, the north town wall is about 375 meters, the eastern town wall is about 285 meters, and the west town wall is about 272 meters, covering an area of 15 acres. Of the four town gates in four directions, only the north town gate is intact.

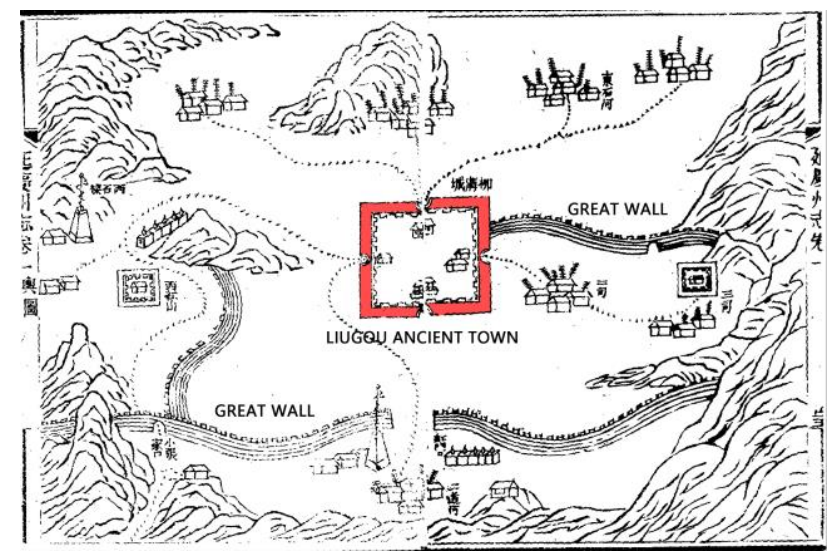

Figure 2. Ancient map of Liugou Town.

\footnotetext{
* Corresponding author
} 


\subsection{Types and Status Quo of the Earthen Sites}

According to different positions and functions in the defense system, the earthen sites in the ancient town of Liugou can be divided into three categories: The Earthen Great Wall, the earthen wall, and brick-encased soil gates.

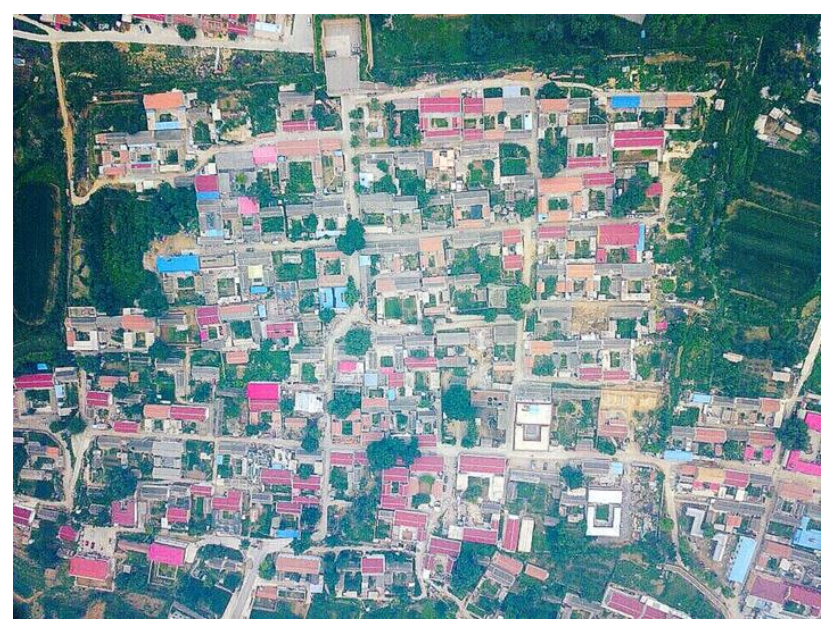

Figure 3. Aerial photo of Liugou Ancient Town.

The Earthen Great Wall: There is a section of rammed earth Great Wall in the southwest of the castle. It is $129 \mathrm{~m}$ long in the east-west direction and $3.5 \mathrm{~m}$ high at the highest point. There is a height difference of $5 \mathrm{~m}$ between the north and south sides of the Great Wall. The earthen wall is continuous as a whole, but the weathering collapse is severe, and the extra height of the west end is only $0.3 \mathrm{~m}$.

The earthen town wall: The total length of the recognizable walls on the ground is $760 \mathrm{~m}$.

- The North Town Wall: It is divided into the east section and west section. The east section is connected to the North Town Gate. It is $239 \mathrm{~m}$ long, with uneven walls and a height of $5 \mathrm{~m}$. Part of the wall was made of stone, and some of the wall heads are severely damaged and severely weathered. The western section is $136 \mathrm{~m}$ long. The quality of the wall head is slightly better than the eastern section, and the highest point is $5 \mathrm{~m}$ high. There is a gap between the western section and the north gate, with a width of $5.6 \mathrm{~m}$, which is suspected to be an artificially excavated passage.

- The East Town wall: It is divided into four sections from north to south. It starts at the junction with the east end of the north wall, with the length of $133 \mathrm{~m}, 83 \mathrm{~m}, 22 \mathrm{~m}$ and 10 $\times 10 \mathrm{~m}$ wall piers at the southeast corner (it is said that there is Kuixing Pavilion), with the height ranging from $3.5 \mathrm{~m}$ to $5.5 \mathrm{~m}$. In general, weathering and collapse are relatively severe, and there are plant damages.

- The West Town wall: It is divided into four sections from north to south. It starts at the junction with the west end of the north wall, $27 \mathrm{~m}$ long, $11 \mathrm{~m}$ long, $13 \mathrm{~m}$ long and $3 \mathrm{~m}$ high, ranging from $0.9 \mathrm{~m}$ to $5 \mathrm{~m}$ high. Part of the wall of the west town has been destroyed because of the construction of the road. The overall defect is severe and in critical condition.
- The South Town Wall: Only a section of the ground at the western end remains, about $1 / 4$ of the entire South Town Wall can be identified. From the southwest corner of the castle to the east, it is $83 \mathrm{~m}$ long, the southwest corner is $5.5 \mathrm{~m}$ high, and the rest is about $3 \mathrm{~m}$ high. The remaining part is severely weathered and collapsed, some wall heads are missing, and some wall thickness is only $30-40 \mathrm{~cm}$.

The brick-encased soil gates: The north gate of the town gate was repaired in the first phase in November 2007, and preliminary restores were made to the town gate coupon hole and some of the town gate's outsourced brick walls. At that time, there was an "L" -shaped the Wengcheng (enclosure outside the town gate) wall $20 \mathrm{~m}$ away from the North Gate. Only the outline was arguable. It was $28 \mathrm{~m}$ long, and the wall was about $4 \mathrm{~m}$ high. The wall is almost entirely non-existent, and some of the remaining walls are weathered, collapsed, and severely cracked. The thickness of the wall at the eastern end is less than $50 \mathrm{~cm}$. In May 2010, the second phase of the restoration project was carried out, repairing $483.3 \mathrm{~m}$ of the north town wall and the town wall of Wengcheng.

\subsection{Influencing factors of the Earthen Sites}

The factors that affect the earthen sites include natural and human-made. Among the natural elements, wind erosion has the most significant impact on above-ground earthen sites and can sometimes cause fatal damage. The exposed rammed earthen wall is severely weathered and collapsed, and weeds are scattered on the wall. Besides, whether it is above ground or underground, rain erosion has also caused considerable damage to earthen sites, and some freezing and thawing damage may occur in winter.

At the same time, with the deepening of urbanization, humanmade destruction has become a problem that cannot be ignored in the earthen sites. For the convenience of life, residents not only crowded, relied on, and borrowed the city walls at will, opening doors and digging holes on the city walls, but also dismantling and misappropriating the city wall bricks arbitrarily, resulting in the castle wall's outsourced brick masonry. Due to years of village construction, part of the city wall has become a road, and the wall has no ground marks.

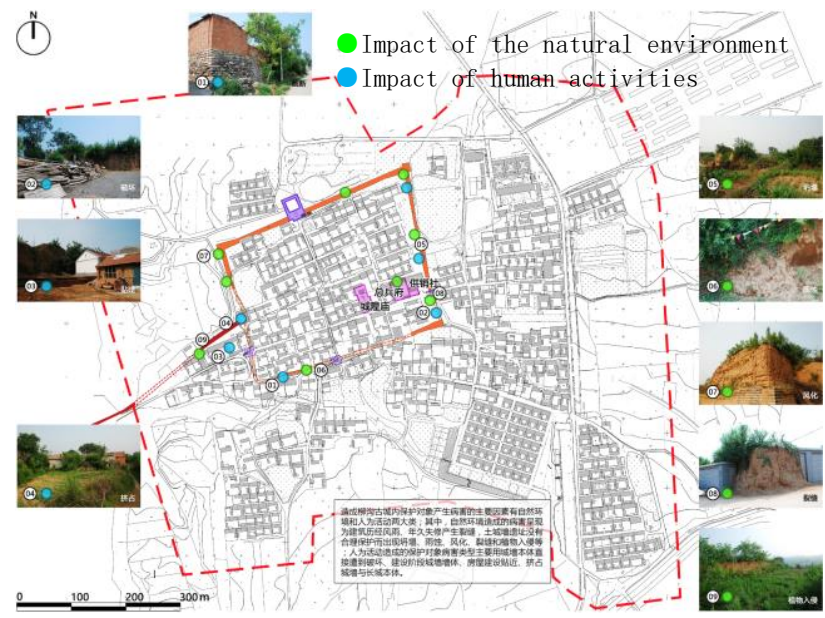

Figure 4. Influencing factors to the earthen sites. 


\section{STUDY ON THE DISEASES OF LIUGOU ANCIENT TOWN EARTHEN SITES}

\subsection{Types of Diseases}

It is found that natural factors cause the primary technical diseases it faces by analysing the geographical and social environment of the earthen sites. Under the combined effects of wind and rain, flaky peeling diseases such as wind erosion peeling, rain erosion peeling, and crack peeling have been produced, undercutting diseases such as blister alkali, wind undercutting, and freeze undercutting, as well as fissured gully diseases and animal and plant organisms damage. The damage caused by human production and life is the leading social disease faced by soil sites. Such diseases are not solved merely by specialized treatment but also involve various factors such as law, economy, security, and stability.

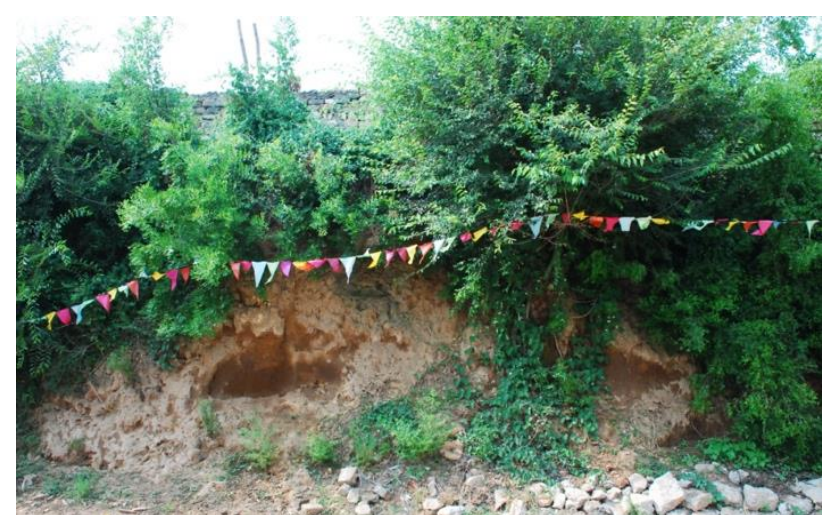

Figure 5. Present situation of peeling diseases of the south town wall.

\subsection{Analysis of central diseases}

The Liugou ancient town earthen sites have many types of diseases with different degrees. This article analyses the three main types:

Weathering and collapse of the rammed earthen wall: The weathering status of the rammed earthen wall of Liugou ancient town earthen sites is divided into a weathered layer, a semiweathered layer, and a slightly weathered layer. The soil structure of the weathered layer is loose, and the lack of cohesion between the soil makes the body of the earthen site extremely vulnerable to wind and rain erosion so that the wall gradually shrinks, and the imbalance eventually collapses. Humans excavate the soil at the bottom of the wall also destroy the stability of the rammed soil structure and cause the collapse.

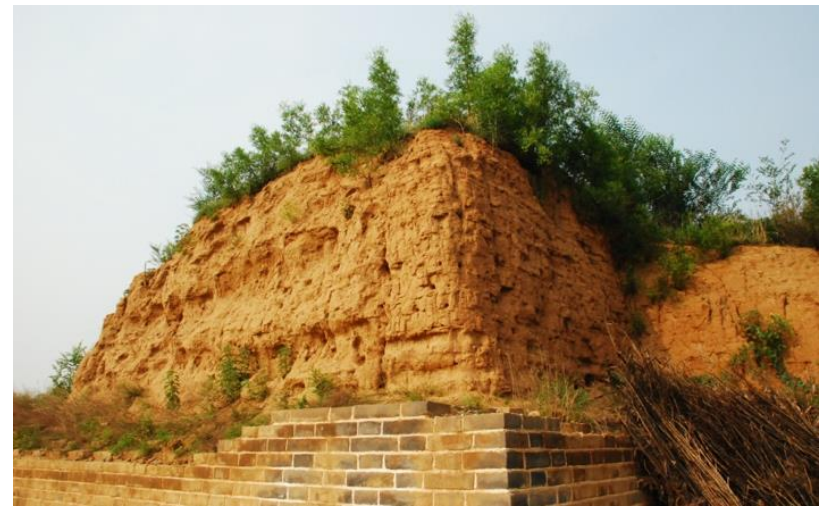

Figure 6. Present situation of weathering and collapse in the northwest corner of the town wall.
Plant diseases: These are the most critical diseases faced by earthen sites. Shrubs and weeds cover the top surface of the earthen sites. The root system of plants grows in the earthen wall cracks, which will not only destroy the original structure of the earthen wall but also cause water to run along with the plant root flow into the wall, which is directly causing the internal soil loss, leading to the problem of hollow and collapse of the wall.

At the same time, plant decay increases the content of organic matter on the surface of soil sites, further aggravates weathering and plant damage. From the perspective of the exhibition, plant growth has reduced the recognition of the ancient earthen wall and has destroyed the authentic town of heritage. Therefore, standard plant removal work is needed.

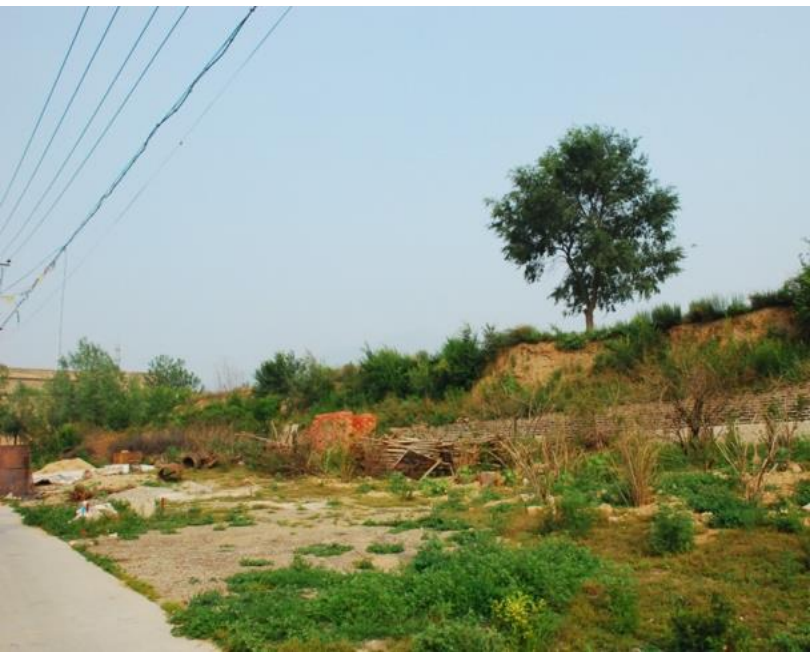

Figure 7. Present situation of plant diseases on the north town wall.

Human-made destruction: Due to the lack of awareness of heritage protection in the early days and the weakening of the defense effect of the earthen wall after the founding of the People's Republic of China, residents dug earth to build houses, resulting in the wall soil being exposed, collapsed and even disappeared. Also, there is no corresponding heritage management in the entire area, and arbitrary climbing and sightseeing by tourists also cause damage to the heritage.

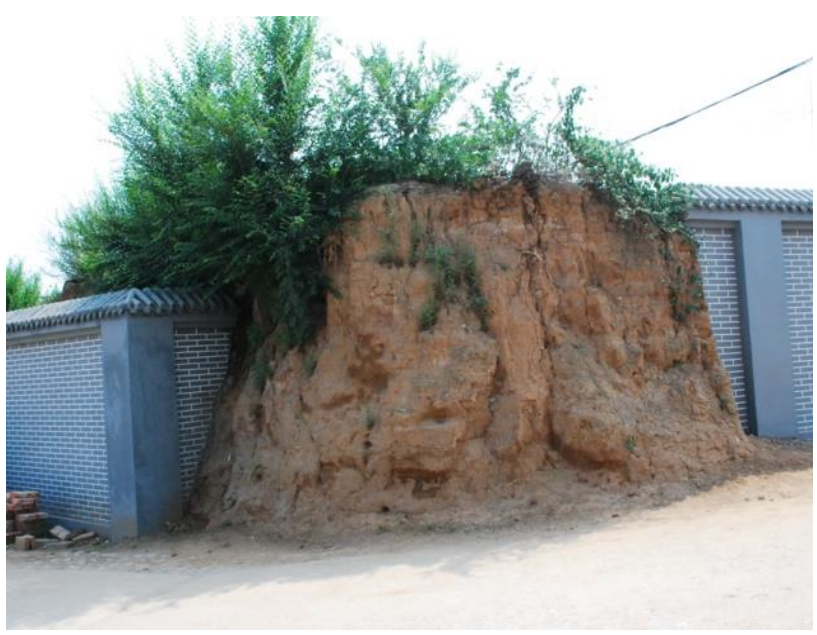

Figure 8. Present situation of human construction damage of the east town wall. 


\section{CONSERVATION AND RESTORATION STRATEGY OF LIUGOU ANCIENT TOWN EARTHEN SITES}

\subsection{Principle of Conservation and Restoration}

Adhere to the "conservation-oriented, rescue first, rational use, and strengthen management" work policy, authentically and integrally protect the historical remains of military castles along the Great Wall and continue its historical information and all values. By establishing technical and regulatory bases, repairing diseases, and stopping new damage to ensure the continuity of cultural heritage. A repair and reinforcement plan must be formulated based on the results of the survey and evaluation and implemented after approval. Meanwhile, the relevance of the various elements of the heritage must be respected.

The various conservation and restoration strategy implemented on the inheritance of the heritage must abide by the principle of not changing the authentic town of the heritage, and the principles of least interference, recognizability, and reversibility. The conservation strategy taken is to continue the status quo and mitigate the damage as the main goals. Before carrying out the conservation project, the surrounding area of the site should be cleaned up first to find out the original shape and original scale. Protecting all historical information on the heritage and respect the original characteristics, including the layout, features and artistic style, the structure and materials, and the crafts.

\subsection{Overall Principle of Conservation and Restoration}

The rescue, repair, reinforcement, and maintenance of the existing Great Wall and earthen town wall are the main contents to be studied at present. The missing part of the town wall can be cleaned and explored first, the location of the town wall can be determined, and the protection measures can be made according to the situation of the ruins. The existing town walls take corresponding repair and reinforcement measures for different diseases. All kinds of buildings and facilities that occupy and rely on the town wall inside and outside should be demolished.

Archaeological work should carry out on the lost gate, which body can partially be restored based on historical data, and the connection with other parts of earthen sites need to be handled well, to improve the enclosure of the overall pattern of Liugou ancient town. For the rammed earthen part of the Great Wall on the west side connecting with the castle, it is suggested to carry out repair and reinforcement according to the characteristics of the earthen site and strengthen the connection between Liugou ancient town and Yanqing Great Wall defense system.

Daily maintenance measures shall be taken for the parts in good condition, without damage and disease and repaired parts, which refers to the regular maintenance without changing the existing structure and appearance of the site.

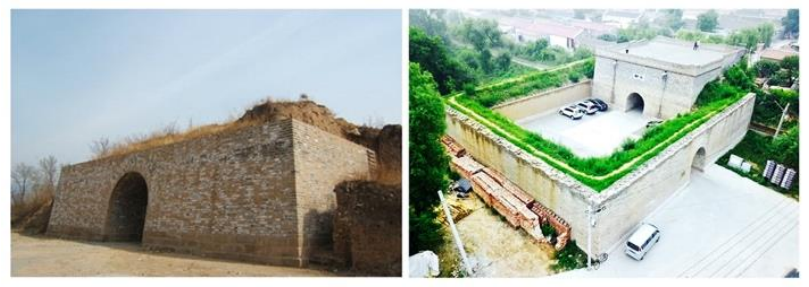

Figure 9. Comparison before and after the repair of the north town gate.

\subsection{Main Techniques of Restoration}

The protection of Liugou ancient town earthen sites should be based on both symptoms and treatment. On the one hand, it should improve its ability to resist damage; on the other hand, it should enhance the damage caused by environment and external factors.

The main restore techniques are as follows:

3.3.1 Reinforce the earthen wall structure: For the loose part of the rammed earthen wall, the method of rammed earth grouting combined with soil anchor and solid phase is adopted.

The internal loose soil is grouted and reinforced so that the inner soil is reunited into a whole, and then the soil anchors are used to anchor the part of the external brickwork. The vertical cracks of the earthen wall are closed with clay plugs to prevent further weathering of the internal soil. For horizontal cracks in the wall, soil anchors need to be used to anchor the soil with a sliding tendency, and then the soil cracks are closed. For the pit formed by the weathering and peeling of the wall, the weathered and loose part shall be cleaned until the stable interface is exposed, and then the rammed earth shall be used for filling. For the pits formed by water scouring, the problem of water leakage needs to be solved, and regular maintenance and overhaul should be performed to avoid leakage of the eaves and leakage of cracks on the top masonry paving, causing internal damage.

The protection of the soil site surface is a combination of spraying protective agents and mud layers. Besides, the repairing material should be cohesive soil, and avoid mixing plant rhizomes, slippery stalks, pests and molds, and plant damage. When rebuilding in a large area, it should be rerammed according to the original method and pattern.

3.3.2 Prevent uneven sedimentation: The ancient town of Liugou is located on the alluvial plain. The terrain is flat overall, but there are many gullies. The downstream water flow is slow, and a large amount of sediment washed down from the upstream is easily caused by uneven sedimentation, which significantly adversely affects the output of the earthen sites structure. Also, the area is located along the Fenwei earthquake zone, which may cause damage, such as a soft foundation's subsidence during the earthquake. Therefore, it is also essential to strengthen the ground. Methods to prevent settlement include root pile reinforcement, grouting and compaction, grouting method, and compaction method. Different measures can be selected and applied according to the specific environment.

3.3.3 Improve the waterproof and drainage systems: The Liugou ancient town earthen sites had a waterproof and drainage system in the early stage of construction. The waterproof layer was paved with lime mortar and brick, which was equipped with a drainage ditch and a spout. However, due to the destruction of multiple factors such as war, these systems have mostly lost their effectiveness. Currently, only the North Town Gate has an entirely waterproof and drainage system through repairs. Therefore, when repairing and strengthening the earthen walls and the earthen Great Wall, temporary or permanent waterproofing measures should be taken, and the drainage system should be dredged and transformed. 


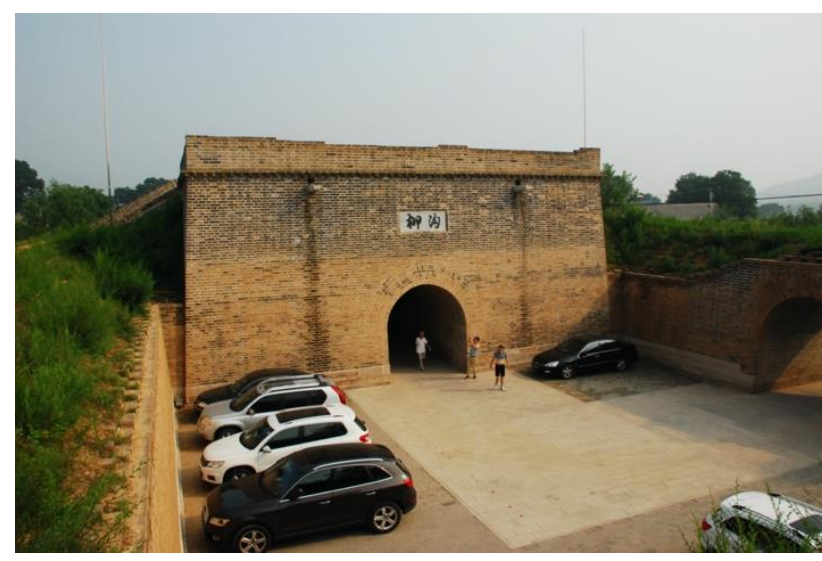

Figure 10. Drainage system of the north town gate.

3.3.4 Clean up the plants: Plants damage is the most typical problem of the Liugou ancient town earthen sites. Not only does the plants' canopy affect the appearance of the city wall, but its root system also becomes a hidden danger that threatens the structure of the town wall. Therefore, cleaning up the plants on the walls and controlling the development of their root systems is the key to conservation. Common vines and shrubs can be removed directly, trees can first cut down their trunks, and then use chemicals to inject the roots. After they rot, add soil to tamp them. Do not directly dig out the roots of the tree, as this is causing more significant damage to the site. If removing the plant is cause the wall to collapse, temporarily retain the plant and treat it after the town wall is repaired and strengthened.

3.3.5 Improve the surrounding environment of earthen sites: Based on the integrity principle of heritage conservation, the protection of the earthen wall should not be limited to the repair and strengthening of the body, but also the environment inside and outside the wall needs to be rectified. For example, the Kuixingge area in the southeast corner of the town wall has been reduced to a massive garbage dump. There are also many houses occupied by the west wall, and Captive sheep are raised near the east wall. These problems have reduced the integrity of the earthen sites. The planning and construction need to be considered systematically.

\section{CONCLUSION}

The Liugou ancient town has outstanding historical value as an essential node of the defense system of the Great Wall. The preservation problems it faces in the context of rapid urbanization have both technical and social attributes, and it is also the epitome of the current dilemma of this type of earthen sites.

Due to the unique nature of their materials and structures, earthen sites are incredibly vulnerable to destruction and damage. Besides, earthen sites in Liugou face double damages of nature and human-made, so the conservation work is urgent. In recent years, a series of repair and reinforcement projects have been carried out under the guidance of relevant departments. However, in the face of many contradictions between rural development and heritage protection, how to move from technology to system and effectively solve the protection of earthen sites is a proposition that needs constant thinking and practice. Based on the historical records of Liugou Town, combined with the research work of conservation planning, this article discusses the strategy of earthen site conservation and restoration from the perspective of repair technology, hoping to provide a reference for the future practical work.
It is hoped that this research can provide not only technical reference for future practical work but also arouse the concern of the academic societies on the conservation predicament of the ancient Great Wall castles. And looking forward to inspiring more strategies for the protection and utilization of earthen sites from multivariant perspectives.

\section{ACKNOWLEDGEMENTS}

I would like to express my sincere gratitude to Professor Zhang Dayu, the corresponding author of this article, for supporting the whole process of research. Thanks to Professor Ouyang Wen, the project leader of Traditional village Conservation and Development Planning of Liugou, for her kind guidance. Thanks to the collaborator Lingege Long for her hard work on this article. At the same time, I want to give appreciates to all the graduate students from the project team for their outstanding contributions in the field investigation.

\section{REFERENCES}

Jing, A., Miao, T., 2008. Analyse the technical method of earth version of the Great Wall, Studies in Chinese Cultural Relics, vol. 2, 51-56.

Lei, H., Lv, J., Wu, T., 2007. Research on Strengthening Technology of Pingyao Ancient City Wall, Building Structure, vol. 1, 140-143.

Ouyang, W., Zhang, D., Gan Z., 2018. Conservation and Development Planning of Liugou Traditional Village in Yanqing of Beijing, Beijing Construction Engineering Institute, Beijing.

Shen, Y., Zhou, X., Chang, J., 2014. Materials and Structures of the Earthen Great Wall in the Ming Dynasty_-Taking Datong Town as an Example, Journal of Southeast University (Natural Science Edition), vol. 2, 205-210.

Sun, M., Wang, X., Li, Z., 2018. Preliminary Discussion of Earthen Site Preservation, China Science Publishing, Beijing.

Tang, Y., Chen, H., Dong Y., 2016. The Construction of the Wal: Chronicles of the Great Wall of China, Phoenix Science Press, Nanjing.

Tang, Y., 2009. Conservation Planning of Liugou Castle Heritage in Yanqing of Beijing, Beijing Construction Engineering Institute, Beijing.

Wang, X., Li, Z., Chen, W., Zhang, H., Guo, Q., Sun, M., Wang, S., Zhang, B., 2014. Research on Key Technologies of Earthen Site Preservation, China Science Publishing, Beijing.

Xu, H., 2014. History of Yanqing, Shaanxi Tourism Press, Xian.

Yang, Y., 2008. Investigation on the Diseases and Conservation Countermeasures of Ancient Earth Walls in Qicheng, Chinese Texts, vol. 1, 91-96.

\section{APPENDIX}

Figures 1 and 4 are drawn by author.

Figure 3, 5, 6, 7, 8, 9 and 10 are photographs by the author. Figure 2 is derived from the 1898 Yanqing Chorography. 